\title{
MADURA FOOT: \\ DESCRIZIONE DI UN CASO CLINICO
}

\author{
Usai F', Carluccio AV', Caddeo R², Pastorelli C², Saddi B' \\ 'Laboratorio Analisi, ${ }^{2}$ Reparto di Dermatologia, \\ Ospedale SS. Trinità, Cagliari
}

Introduzione. Il micetoma è un'infezione granulomatosa cronica del tessuto sottocutaneo causata da alcuni funghi (eumicetoma) o da batteri con morfologia filamentosa e ramificata, appartenenti al gruppo degli "actimomiceti aerobi" (actinomicetoma). Le forme localizzate al piede sono le più frequenti e vengono denominate "Piede di Madura". È riportata la descrizione di un caso di actinomicetoma del piede, causato da Actinomadura madurae.

Caso clinico. Paziente di 44 anni, razza bianca, sesso femminile, nata e vivente in Sardegna, dedita ad attività agricole. Nel marzo 2004, al momento della nostra prima osservazione, il piede destro della paziente appariva tumefatto, di dimensioni doppie rispetto al controlaterale. L'esame microscopico di un campione prelevato da una fistola esterna del piede, evidenziava la presenza di aggregati di sottili formazioni filamentose e ramificate, Gram-positive; l'esame colturale, dopo due settimane di incubazione a $37^{\circ} \mathrm{C}$ in aerobiosi, portava all'isolamento su agar sangue e agar cioccolato di piccole colonie coriacee, cerebriformi, dapprima biancastre, poi pigmentate in rosso-arancio. Il ceppo risultava resistente al cotrimoxazolo, pertanto la paziente veniva sottoposta a trattamento con imipenem + doxiciclina, con significativa remissione delle manifestazioni cutanee. Succesivamente, il ceppo isolato è stato identificato come Actinomadura madurae, grazie al cortese interessamento della Prof.ssa A. M. Tortorano, dell'Istituto di Igiene di Milano. Nel marzo 2005, in seguito ad una riacutizzazione delle lesioni cutanee e alla comparsa di lesione ossee, sono stati eseguiti nuovi accertamenti microbiologici, che portavano ad un secondo isolamento colturale del ceppo di $A$. madurae in causa. La paziente veniva sottoposta ad un trattamento per via orale con linezolid; dopo il primo ciclo di terapia, si osservava una completa risoluzione delle manifestazioni cutanee, ed una riduzione delle lesioni ossee.

Discussione. Nei Paesi in cui il micetoma è una patologia poco conosciuta, l'actinomicetoma è spesso scambiato per eumicetoma, come peraltro accaduto nel caso clinico in esame. Pertanto, l'isolamento colturale del microrganismo infettante è sempre auspicabile per confermare l'eziologia della diagnosi clinica ed istopatologica, e per instaurare un'adeguata terapia, sulla base dell'antibiogramma. I risultati clinici finora ottenuti, suggeriscono di considerare il linezolid come una possibile opzione terapeutica per l'actinomicetoma. 